\title{
An Educational Adventure Game for Teaching Information Literacy and Student Engagement
}

\author{
Myungjae Kwak \\ Middle Georgia State University \\ myungjae.kwak@mga.edu
}

\author{
Alex Koohang \\ Middle Georgia State University \\ alex.koohang@mga.edu \\ Anthony Choi \\ Mercer University \\ choi_ta@mercer.edu
}

\author{
Kevin Floyd \\ Middle Georgia State University \\ kevin.floyd@mga.edu
}

\begin{abstract}
The focus of games has broadened beyond entertainment purposes to serve as a vital tool in other areas including education, business, and health. In this paper, a 2D educational adventure game is presented and evaluated. The purpose of the game is to teach college students several important aspects of information literacy. Students are expected to become comfortable with various concepts of information literacy such as keyword searches, identifying sources, and proper reference citing. To better engage students, the game progresses around an interesting adventure story and uses seven mini games designed to teach basic information literacy concepts. The evaluation results show a very promising future for the game.
\end{abstract}

\section{Introduction}

Games have been developed not only for entertainment but also as effective tools for educating, motivating, and changing behavior [1]. Various studies show that serious games can be effectively used to facilitate deep and sustained learning [2, 3, 4]. Games are also making their way into education as a means of helping to motivate and engage students during the learning process.

In this paper, we present an educational game, Tesla's Revenge, designed and developed by a group of university students, librarians, and faculty to teach various information literacy concepts to college freshmen and sophomore students [5, 6]. The overall focus of the game is to increase a college student's information literacy through the introduction of an interactive learning tool.

Our educational game is intended to be used in information literacy courses for college freshmen and sophomores. In the game, an innovative and engaging adventure story cushions the learning concepts to provide an alternate method for obtaining knowledge about a specific concept. An interactive and branching dialog system is used to enforce learning by trial-anderror. The game includes a series of mini games that have been designed to teach various information literacy concepts. The game consists of three acts. The level of difficulty increases with each act, and serves to build upon learned concepts and assess a student's comprehension of concepts. The rate of completion for in game tasks indicates whether or not a student has learned and understood a concept or requires more practice.

We evaluated the game using the pre-test and posttest method to see if the design of the game would work as intended. In comparing the pre- and post-tests, the evaluation results showed a significant performance improvement.

\section{Related Work}

Several studies have been conducted to determine the benefits of using games for informal learning and transformative education $[7,8,9,10,11]$. Educational game researchers typically implement their games to encourage problem-based, experiential, engaged, and situational learning and support deep learning by providing immediate feedback, personalization, and challenges $[9,12,13,11]$. While a number of studies show the positive effects of educational games $[14,15$, $16,17,18]$, some studies report neutral results or little effect $[19,20,21,22,23]$. Therefore, we believe that much more study and research is needed for effective design and implementation of educational games.

Games have been used in many different educational settings. Morrison and Preston studied how gaming has been suffused into the curriculum of major universities 
in the United States and found that many programs use gaming in their introductory courses to increase motivation and improve retention [3].

Librarians also have been using games to teach information literacy to college students, but their attempts have not been much successful. Van Leer laments the quality of "games" that librarians have been using, stating that these games are more of a vehicle for exposition [24]. These games often lack the element of interaction that users expect from games. Moreover, such games come across as quizzes or tutorials rather than something that is played for enjoyment. Gee argues that a good game should be interactive, give the player feedback, and expose them to new and well-ordered problems, a concept very similar to the idea of scaffolding [25]. With this approach, the problems encountered by the player should be solvable based on the knowledge that they have acquired and built upon during the course of the game.

Schiller examines the similarity between the principles of sound game design and sound instruction by analyzing the elements of teaching and learning utilized in the video game Portal from Valve Software [26]. Within the game, the player is asked to complete tasks that become more complex as the game progresses. Schiller reasons that the game design provides "more intervention to players who need it most and then gradually removes support as players demonstrate a skill level that allows them to stand on their own" [26].

Schiller also analyzed the merits of Portal's game design as a model for effective instructional design and claimed that there is value in learning through trial and error and that this is something that Google and the idea of federated searching has taken away due to their focus on ease of use [26]. The focus on ease of use means that failure is not always visible to the user. Even if your search fails, there will be results on the page, this takes away the element of "trial and error." If the search hides your failure, where is your motivation to try something else, or to try to find better results? It could be argued that this is the true challenge for effective instruction through interactive learning to make failure not only evident, but a part of the learning process.

Games are structured in such a way as to make difficulties and challenges not only expected but also enjoyable. Gumulak and Webber found that the students they interviewed found long and difficult games are more enjoyable because of the excitement and sense of achievement that they felt when these obstacles are overcome [27]. Gumulak and Webber's study examines the nature of gaming, learning, and literacies among teenagers. They set out to investigate the various ways that teenagers interact with video games. A qualitative study was run on a convenience sample of 28 young people from five local schools, in Northern England, with interviews taking place in 2009. The sample group was predominantly male, comprised of 24 males and 4 females ranging in age between 11 and 17 years old. Questions focused on identifying the types of games that the interviewees played and enjoyed, how they selected games, and what they enjoyed about them [27].

Interviews were recorded and transcribed verbatim. Transcripts were read and analyzed with emphasis on verbal cues related to information behavior, literacy, and learning. The main reasons cited by study respondents for playing games are "challenge" and "entertainment." Interviewees also indicated seeking out games that were long and difficult. The most frequently mentioned type of game played was the firstperson shooter, a game where you see the world through the eyes of your chosen player and the objectives are usually killing other people or creatures [27]. When asked about game related learning, students seemed to have a harder time connecting their efforts within the game to real world learning, and older respondents were especially hesitant to identify game related learning [27]. While some students mentioned problem solving as a learning feature, others mentioned that learning how to play the game was applicable to real world learning.

The study also identified elements of textual literacy that can be associated with gameplay. Interviewees would identify keywords and meanings in on screen text to solve in-game problems, or determine what to do next. If they were having issues with gameplay, they would realize that the text and provided information within the game could help them progress. This demonstrated that they could identify an information need, and were able to use resources to find necessary information to satisfy it. In summary, study participants did make active use of the text within the games to improve gameplay and solve problems within the game world [27]. The study also suggested that young people are "focused on finding information to solve problems" and that they want to discover information and apply it. Games that focus too much on finding information but not enough on using it to solve a problem may not keep the player's attention [27]. They concluded that an attractive appearance, effective gameplay and relevant activities that are specific to the context, and goals of the learner are key components to creating enthusiasm when implementing well-planned game based learning.

Csikszentmihalyi [28] defines flow as a mental state of complete absorption in an activity [29]. In the flow state, a person is completely focused and motivated, and enjoys the activity. Moreover, emotions are not just contained and channeled, but positive, energized, and aligned with the task at hand [29, 28]. 
While "serious games," which date back several millennia [30], denote full-fledged games designed for non-entertainment purposes [31], "gamified" applications incorporate elements of games [32, 31]. Reeves and Read [33] identified the "Ten Ingredients of Great Games": self-representation with avatars; threedimensional environments; narrative context; feedback; reputations, ranks, and levels; marketplaces and economies; competition under rules that are explicit and enforced; teams; parallel communication systems that can be easily configured; time pressure [31].

Ralph and Monu proposed a unified theory of digital games by reconciling the Mechanics-DynamicsAesthetics framework and the Elemental Tetrad [34]. The proposed theory differentiates game mechanics from narrative mechanics, distinguishes three types of narratives including embedded narratives, emergent narratives, and players' interpretations of these narratives, and clarifies the meaning of aesthetics and dynamics within game studies [34].

\section{Game Design and Development}

The design goal of our educational game was to provide a significant contribution to this promising, albeit partially established, field by incorporating immersive 2D virtual worlds with educational games, and by evaluating its effectiveness using experimental design. Immersive gaming features $[35,36]$ have been successfully used in a number of 2D educational games.

We believe that Tesla's Revenge's combination of immersive 2D virtual worlds and game story is likely to facilitate flow experience [29, 37]. With neither fear nor frustration, and the appeal of exploration, students are fully absorbed in playing mini-games, and gain a deeper understanding of information literacy while learning how to apply this understanding to new problems.

Designing and developing a game usually requires an iterative process and the first version of a game can be radically different from the final version. Such is the case with our game, Tesla's Revenge. The first version of this game was titled Chasing the Truth, a mystery narrative, and it lacked many features of an entertaining educational game, the most important being an overall lack of fun [5]. The previous version was not enjoyable to play in many ways as it was too linear and unengaging in the gameplay. It was more of an instructional software that uses little gaming features and focuses on transferring knowledge. Therefore, the development team decided to rebuild the overall design of the game.

The new version of the game was designed to include a set of 'game elements', which was identified by previous studies $[33,31]$, to better engage the game players. Out of the ten ingredients of games identified by Reeves and Read [33], the following six items were incorporated into the game: self-representation with avatars; narrative context; feedback; reputations, ranks, and levels; competition under rules that are explicit and enforced; time pressure.

\subsection{Engaging Game Story and Gameplay}

In the new version of the game, an innovative, engaging adventure story is introduced to increase the learning effects by better engaging players. It becomes a mystery adventure game in which the player is a student in a library. When a mysterious malefactor blasts a hole in the middle of the building, the player is sent on a journey to uncover the mystery regarding who would cause such destruction and what would serve as the primary motivation for such destruction. Figure 1 shows the game level depicting the destroyed library.

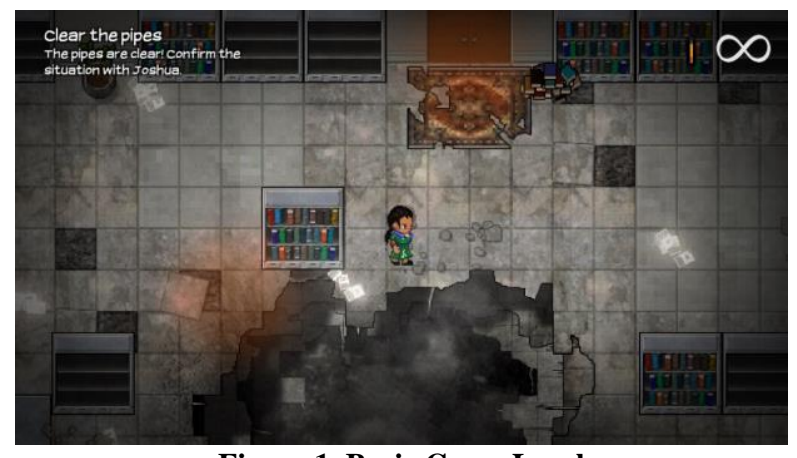

Figure 1. Basic Game Level

The identity of the perpetrator remains unknown to the player until the end of the game. At the end of the game it is revealed that the enemy is an undead Nikola Tesla who is consumed with enacting revenge on the world for forgetting about his scientific contributions. Tesla uses his death beam invention to etch a hole in the middle of the library. The death beam is appropriately named for its ability to destroy any object through which it passes. Beyond its ability to enact death, the death beam also releases chaotic energy that infuses objects around the library and turns them into monstrous creatures.

The game is split into three major scenes and progress in the story is made by completing Quests and speaking to specific people in the library (see Figure 2). Each of these scenes takes place on one of the floors of the building. Throughout the game, players are confronted with creatures that have been infected with the chaotic energy (see Figure 3). Each encounter with the creatures opens a mini game, which is used to teach specific types of information literacy concepts. Figure 4 shows a mini-game for correcting punctuation errors. 


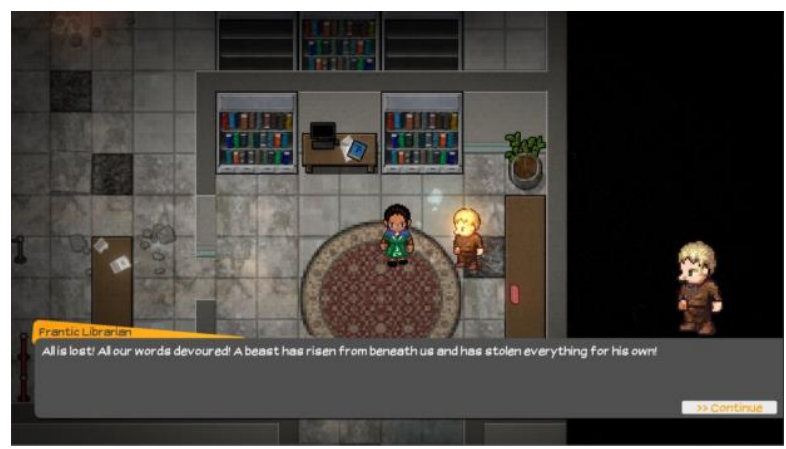

Figure 2. Talking to librarian

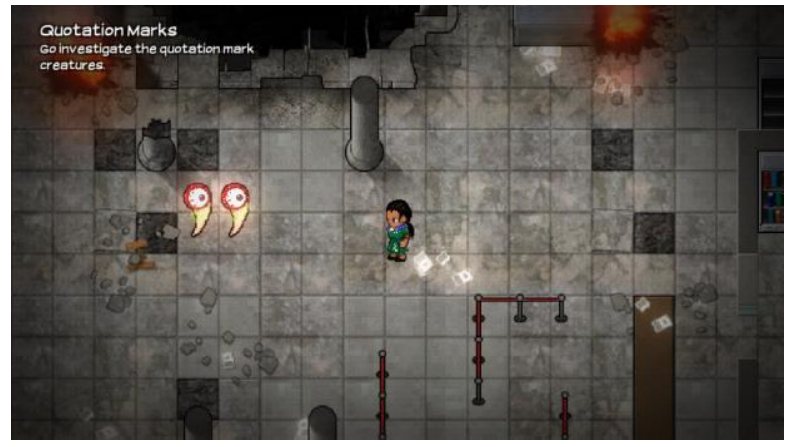

Figure 3. Confronting Monstrous Creature, Quotron

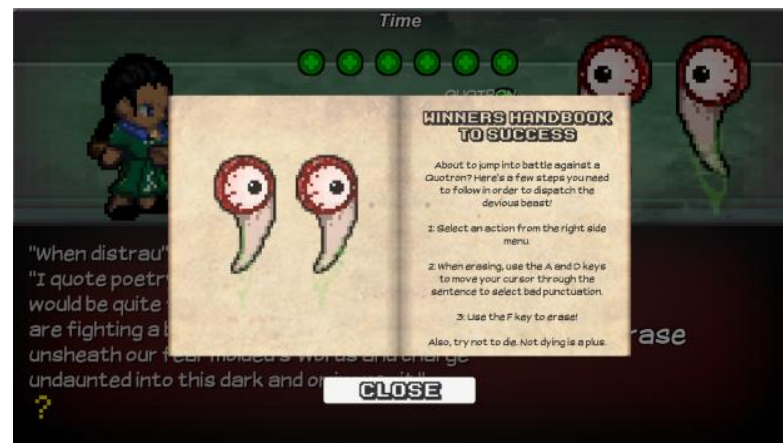

Figure 4. Mini-Game for Correcting Punctuation Errors

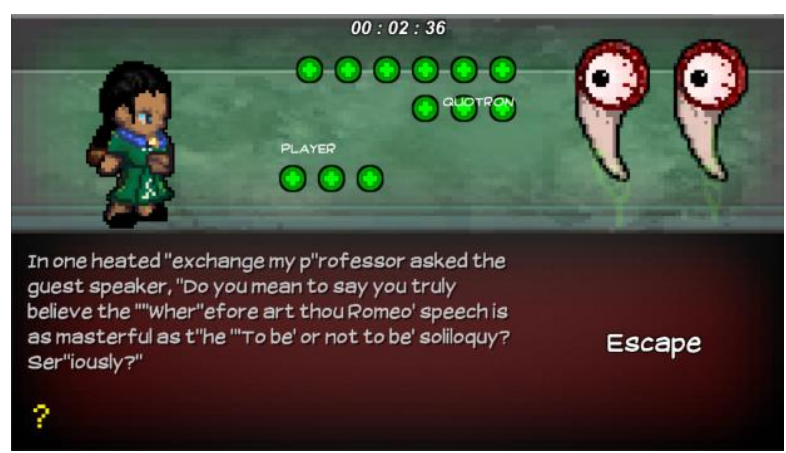

Figure 5. A Scene of the Quotron Mini-Game

The first enemy the player encounters in the game is Quotron, a giant pair of floating double quotation marks (see Figure 5). The creature is ugly and intimidating, but if the player successfully removes the incorrect punctuation in the mini-game, the Quotron will be eradicated. There are a total of 7 mini-games have been developed including Quotron, Water Pipes (see Figure 6), Keyword Search (see Figure 7), Powerbox (see Figure 8), Book Cart (see Figure 9), Runner, and Terminal. Each mini-game was designed to teach a specific type of information literacy and include game elements that improve engagement (see Table 1). The keyword search game is designed to teach students how to recalibrate the search engine within the library computers, and the water pipes mini-game was designed to teach citation concepts. These mini-games have three purposes: to engage and entertain the player, teach a concept of information literacy, and progress the story.

Table 1. Design Goals and Game Elements of Mini-games

\begin{tabular}{|l|l|l|}
\hline Mini-games & Learning Objectives & \multicolumn{1}{|c|}{ Game Elements } \\
\hline Quotron & $\begin{array}{l}\text { Proper use of } \\
\text { quotation marks }\end{array}$ & $\begin{array}{l}\text { Avatar, levels; rules, } \\
\text { time }\end{array}$ \\
\hline Water Pipes & $\begin{array}{l}\text { Identification of parts } \\
\text { of an article }\end{array}$ & $\begin{array}{l}\text { Avatar, levels, rules, } \\
\text { time }\end{array}$ \\
\hline $\begin{array}{l}\text { Keyword } \\
\text { Search }\end{array}$ & $\begin{array}{l}\text { Proper use of search } \\
\text { keywords }\end{array}$ & Levels, rules, time \\
\hline Powerbox & $\begin{array}{l}\text { Correct use of } \\
\text { AND/OR operator }\end{array}$ & Levels, rules, time \\
\hline Book Cart & $\begin{array}{l}\text { Selection of an } \\
\text { appropriate resources }\end{array}$ & Levels, rules, time \\
\hline Runner & $\begin{array}{l}\text { Appropriate use of } \\
\text { punctuations }\end{array}$ & $\begin{array}{l}\text { Levels, rules, } \\
\text { feedback, time }\end{array}$ \\
\hline Terminal & $\begin{array}{l}\text { Proper citation of } \\
\text { resources }\end{array}$ & Levels, rules, time \\
\hline
\end{tabular}

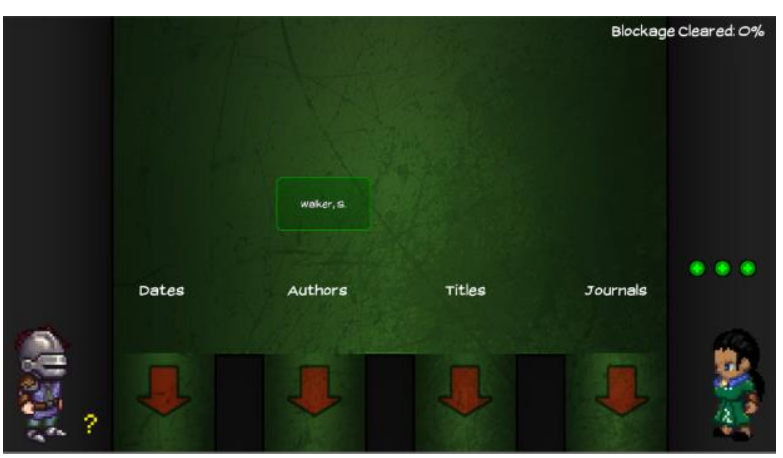

Figure 6. Water Pipes Mini-Game

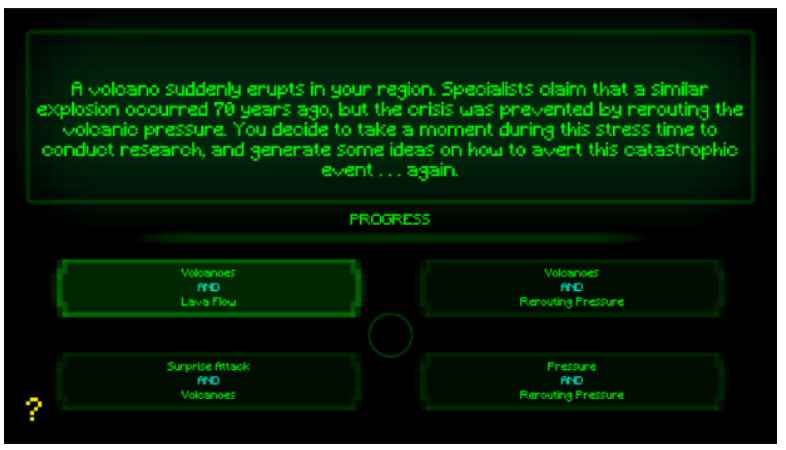

Figure 7. Keyword Search Mini-Game 


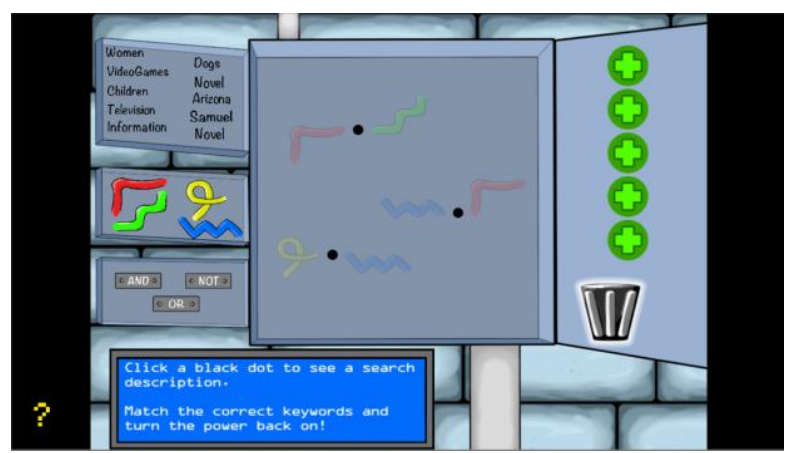

Figure 8. Powerbox Mini-Game

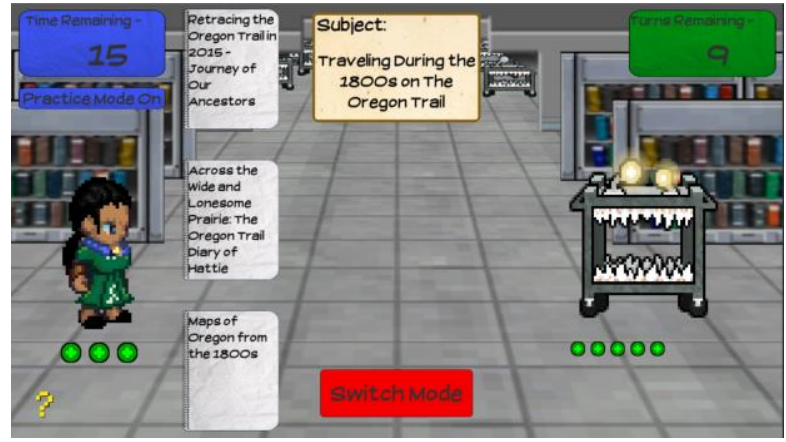

Figure 9. Book Cart Mini-Game

\subsection{UI Design and Development}

Tesla's Revenge is a 2D, 8-bit style game (see Figure 1 ). The art style is modeled after older $2 \mathrm{D}$ games. The style was chosen for the game because game designers and programmers thought it would make the game appealing and engaging to any age player.

The game has been developed using the Unity 3D game engine. Unity, a powerful and versatile tool, has been an integral part of the developmental process. The game uses keyboard input to control the character and mouse interaction for extra control. The player may control their character with the arrow keys and the " $\mathrm{F}$ " key to interact with the world. Mini games are controlled in a similar fashion.

The User Interface (UI), what the player sees on the screen, is very simple. The Quest panel can be found in the top left corner, and the player can access the panel to see what quests need to be accomplished during a specific phase of the game. The inventory system for the game was built by using Unity's UI system. The player knows what he or she is currently holding by looking at the inventory system. A dialogue system has also been designed and developed for the game. The dialogue system allows players to interact and converse with other non-playable characters (NPCs) within the game. Players will be able to extract vital information from these non-playable characters regarding what is going on or what quest to follow.

\section{User Study Evaluation}

\subsection{Experiment Design and Evaluation Metrics}

The game was evaluated using the pre-test and posttest method to see if the design of our 2D adventure game is effective in teaching information literacy. We designed two sets of seven questions to evaluate seven different concepts of information literacy, each taught in a mini-game. One set of the seven questions is used for the pre-test and the other set for the post-test (see Appendix).

We recruited forty-eight (48) college students who needed to take a basic information literacy course required by the university and taught by a librarian. Table 2 shows the basic demographics of the participants.

Table 2. Demographics of Participants

\begin{tabular}{|c|c||c|c|c|c|}
\hline Age & & Gender & & Ethnic & \\
\hline$<18$ & 3 & Male & 39 & $\begin{array}{c}\text { African- } \\
\text { American }\end{array}$ & 17 \\
\hline $18-25$ & 40 & Female & 9 & Asian & 2 \\
\hline $26-33$ & 4 & & & Caucasian & 26 \\
\hline $34-41$ & 1 & & & Hispanic & 3 \\
\hline$>42$ & & & & Others & 0 \\
\hline
\end{tabular}

Out of the forty-eight students, twenty-four were randomly assigned to the control group and twenty-four to the experimental group. Both groups took the pre-test. Then the control group was taught for an hour by the librarian in a traditional information literacy course using Power point slides and course materials. The experimental group played the game for about an hour, after a brief introduction of the game instead of taking the traditional information literacy course taught by the librarian. Then both groups took the post-test. Next, two librarians grade the seven questions using the 5-point Likert scale. The answers were graded from 1 (very bad) to 5 (very good).

We calculated the mean value of the grades of the seven questions and conducted paired-samples $t$-test to compare the pre and post-test results, and conducted an independent-samples $t$-test to see the difference between the control group and experiment group.

\subsection{Results}

Table 3 shows the descriptive statistics of the pre and post-test results of both control and experimental groups. As expected, both post-test results show that 
student grade was improved after taking the information literacy course or playing the game.

Table 3. Descriptive Statistics

\begin{tabular}{|l|l|c|c|c|}
\hline Group & Test & Mean & N & S.D. \\
\hline \multirow{2}{*}{ Control } & Pre & 3.68 & 24 & .45 \\
\cline { 2 - 5 } & Post & 4.14 & 24 & .26 \\
\hline \multirow{2}{*}{ Experiment } & Pre & 3.54 & 24 & .56 \\
\cline { 2 - 5 } & Post & 4.58 & 24 & .24 \\
\hline
\end{tabular}

Table 4 shows the results of the paired-samples ttest. The paired-samples t-test between pre and post-test results of the condition group showed that the difference between the pre and post-test results is statistically significant $(t(23)=-5.07, \mathrm{p}<0.001)$. In addition, the paired-samples t-test between pre and post-test results of the experiment group showed that the difference between the pre and post-test results is statistically significant $(t(23)=-8.23, \mathrm{p}<0.001)$. In both groups, the post-test results produced a significant improvement.

Table 4. Paired-samples t-test

\begin{tabular}{|l|r|r|r|r|r|}
\hline \multicolumn{1}{|c|}{ Pair } & Mean & S.D. & \multicolumn{1}{c|}{ t } & df & Sig.(2-tailed) \\
\hline $\begin{array}{l}\text { Control } \\
\text { (pre-post) }\end{array}$ & -.47 & .45 & -5.07 & 23 & .000 \\
\hline $\begin{array}{l}\text { Experiment } \\
\text { (pre-post) }\end{array}$ & -1.05 & .62 & -8.23 & 23 & .000 \\
\hline
\end{tabular}

We also conducted an independent-samples t-test to examine whether or not playing the library game outperforms the traditional information literacy class. The t-test results show that the difference between the post-test results of the two groups is statistically significant $(t(46)=-5.994, \mathrm{p}<0.001)$. This means the post-test results of the experiment group produced a significant improvement and playing the library game could be better than taking a traditional information literacy course.

Table 5. Independent-samples $t$-test between post-test results of the condition and experiment groups

\begin{tabular}{|l|c|c|c|}
\hline & t & df & Sig.(2-tailed) \\
\hline Post Test & -5.994 & 46 & .000 \\
\hline
\end{tabular}

* Levene's Test for Equality of Variances (F(.023), Sig.(.880))

\subsection{Discussions}

To further analyze the experiment results, we also asked several open-ended questions of the participants including whether they think the game is useful for improving their information literacy skills. Twentythree $(96 \%)$ of the twenty-four subjects of the experimental group answered that the game helped somewhat or very much and only one participant responded that it did not help.
Regarding the question about what they like the most about the game, seven $(29 \%)$ of the players pointed to the story of the game and six $(25 \%)$ picked game action and play. Table 6 shows the most-liked features of the game.

Table 6. Most-liked features of the game

\begin{tabular}{|l|c|}
\hline \multicolumn{1}{|c|}{ Game Features } & \# of Subjects \\
\hline Game Story \& Narrative & $7(29 \%)$ \\
\hline $\begin{array}{l}\text { Game Mechanics \& Action (like playing } \\
\text { an actual game) }\end{array}$ & $6(25 \%)$ \\
\hline Game Avatars \& Characters & $4(17 \%)$ \\
\hline Difficulty Levels and Feedback & $3(13 \%)$ \\
\hline Graphics (Aesthetics) & $3(13 \%)$ \\
\hline
\end{tabular}

We think that the experiment results and answers to the open-ended questions show that the learning goals of the game were achieved by incorporating various game elements such as an interesting story, avatars, game action, narrative context, game rules, feedback, difficulty levels and time pressure.

\section{Conclusion and Future Work}

Educational games could provide students with alternate methods of learning and understanding subjects. While it needs to be further analyzed and examined, the preliminary evaluation results show a very promising future for the $2 \mathrm{D}$ educational adventure game presented in this paper, It could offer instructors an innovative and engaging way to promote student interest and comprehension.

Considering the test results including the effectiveness of each mini-game and player feedback, we argue that the learning goals of the library game were achieved. In the future, we plan to fully analyze the evaluation results and enhance the game further by referring to the test results and feedback. In addition, we plan to open this game to the public, gather and analyze more detailed gaming data of user behaviors, and publish the analysis results.

\section{References}

[1] U. Riterfield, M. Cody and P. Vorderer, Serious games: mechanisms and effects, New York: Routledge, 2010.

[2] J. Gee, Good Video Games and Good Learning: Collected Essays on Video Games, Learning and Literacy, 1st ed., New York: Peter Lang International Academic Publishers, 2007.

[3] B. B. Morrison and J. A. Preston, "Engagement: gaming throughout the curriculum," $A C M$ 
SIGCSE Bulletin, vol. 41, no. 1, pp. 342-346, March 2009.

[4] E. Soloway, M. Guzdial and K. E. Hay, "Learner-centered design: The challenge for HCI in the 21 st century," interactions, vol. 1, no. 2, pp. 36-48, 2004.

[5] D. Casper, C. Talmage, S. Hollifield, C. Nylund and M. Kwak, "Chasing the Truth: An Educational Game for Information Literacy and Student Engagement," in 18th of Southern Association for Information Systems Conference (SAIS), Hilton Head, South Carolina, 2015.

[6] C. Talmage, S. Hollifield, D. Casper, J. Brooks, J. Holland, C. Nylund, A. Choi and M. Kwak, "Tesla's Revenge: A 2D Educational Adventure Game for Information Literacy and Student Engagement," in SAIS 2016 Proceedings, 2016.

[7] C. Aldrich, The Complete Guide to Simulations and Serious Games: How the Most Valuable Content Will be Created in the Age Beyond Gutenberg to Google, Pfeiffer, 2009.

[8] S. Egenfeldt-Nielsen, Beyond Edutainment: The Educational Potential of Computer Games, Continuum Press, London, UK, 2007.

[9] J. Gee, What Video Games Have To Teach Us about Learning and Literacy, Palgrave Macmillan, New York, NY, 2003.

[10] D. Shaffer, How computer games help children learn, Palgrave Macmillan, New York, NY, 2006.

[11] K. Squire, Video games and learning: Teaching and participatory culture in the digital age, Teachers College Press, New York, NY, 2011.

[12] S. De Freitas and P. Maharg, Digital Games and Learning, Continuum Press, London, UK, 2011.

[13] J. Gee, Good games and good learning, Peter Lang Publishing, New York, NY, 2007.

[14] S. Barab, M. Thomas, T. Dodge, R. Carteaux and H. Tuzun, "Making learning fun: Quest Atlantis, a game without guns," Educational Technology Research and Development, vol. 53, no. 1, pp. 86-107, 2005.

[15] D. Clark, B. Nelson, H. Chang, C. D’Angelo, K. Slack and M. Martinez-Garza, "Exploring Newtonian mechanics in a conceptuallyintegrated digital game: Comparison of learning and affective outcomes for students in Taiwan and the United States," Computers and Education, vol. 57, no. 3, p. 2178-2195, 2011.

[16] C. Harteveld, Making sense of virtual risks: A quasi-experimental investigation into game- based training., IOS Press, Amsterdam, the Netherlands, 2012.

[17] F. Ke and B. Grabowski, "Gameplaying for maths learning: Cooperative or not?," British Journal of Educational Technology, vol. 38, no. 2, p. 249-259, 2007.

[18] E. Klopfer and K. Squire, "Environmental detectives: The development of an augmented reality platform for environmental simulations," Educational Technology Research and Development, vol. 56, no. 2, pp. 203-228, 2008.

[19] T. Connolly, E. Boyle, E. MacArthur, T. Hainey and J. Boyle, "A systematic literature review of empirical evidence on computer games and serious games," Computers and Education, vol. 59, no. 2, pp. 661-686, 2012.

[20] C. Girard, J. Ecalle and A. Magnan, "Serious games as new educational tools: How effective are they? A meta-analysis of recent studies," Journal of Computer Assisted Learning, vol. 29, no. 3, pp. 207-219, 2013.

[21] H. O’Neil, R. Wainess and E. Baker, "Classification of learning outcomes: Evidence from the computer games literature," The Curriculum Journal, vol. 16, no. 4, pp. 455-474, 2005.

[22] J. Vogel, D. Vogel, J. Cannon-Bowers, C. Bowers, K. Muse and M. Wright, "Computer gaming and interactive simulations for learning: A meta-analysis," Journal of Educational Computing Research, vol. 34, no. 3, pp. 229-243, 2006.

[23] M. Young, S. Slota, A. Cutter, G. Jalette, G. Mullin, B. Lai, Z. Simeoni, M. Tran and M. Yukhymenko, "Our Princess Is in Another Castle: A Review of Trends in Serious Gaming for Education," Review of Educational Research, vol. 82, no. 1, pp. 61-89, 2012.

[24] L. VanLeer, "Interactive Gaming Vs. Library Tutorials for Information Literacy: A Resource Guide," Journal of the Indiana Library Federation, vol. 25, no. 4, 2006.

[25] J. P. Gee, "Good video games and good learning," Phi Kappa Phi Forum, pp. 33-37, 2005.

[26] N. Schiller, "A portal to student learning: what instruction librarians can learn from video game design," Reference Services Review, pp. 351-365, 2008.

[27] S. Gumulak and S. Webber, "Playing video games: learning and information literacy," Aslib Proceedings, vol. 63, no. 2/3, pp. 241-255, 2011. 
[28] M. Csikszentmihalyi, Flow, Springer Netherlands, 2014.

[29] W. Admiraal, J. Huizenga, S. Akkerman and G. t. Dam, "The concept of flow in collaborative game-based learning," Computers in Human Behavior, vol. 27, pp. 1185-1194, 2011.

[30] C. C. Abt, Serious games, University press of America, 1987.

[31] S. Deterding, D. Dixon, R. Khaled and L. Nacke, "From game design elements to gamefulness: defining gamification," in 15th international academic MindTrek conference: Envisioning future media environments, 2011.

[32] B. Brathwaite and I. Schreiber, Challenges for Game Designers, Charles River Media, 2008.

[33] B. Reeves and J. L. Read, "Total engagement. Using Games and Virtual Worlds to change the way people work and businesses compete," International Journal of Gaming and ComputerMediated Simulations, vol. 3, no. 2, pp. 78-84, 2011.

[34] P. Ralph and K. Monu, "Toward a unified theory of digital games," The Computer Games Journal, vol. 4, no. 1-2, pp. 81-100, 2015.

[35] C. S. González and F. Blanco., "Integrating an educational 3D game in Moodle," Simulation \& Gaming, 2008.

[36] D. Coyle, M. Matthews, J. Sharry, A. Nisbet and G. Doherty, "Personal Investigator: A therapeutic 3D game for adolecscent psychotherapy,"
Interactive technology and smart education, vol. 2, no. 2, pp. 73-88, 2005.

[37] C. Dede, "Immersive interfaces for engagement and learning," Science, vol. 323, no. 5910, pp. 66-69, 2009.

[38] M. A. Smale, "Get in the Game: Developing an Information Literacy Classroom Game," Journal of Library Innovation, vol. 3, no. 1, pp. 126-147, 2012.

[39] B. Winn and C. Heeter, "Resolving conflicts in educational game design through playtesting," Innovate: Journal of Online Education, vol. 3, no. 2, 2007.

[40] C. Conati and X. Zhao., "Building and evaluating an intelligent pedagogical agent to improve the effectiveness of an educational game," in Proceedings of the 9th international conference on Intelligent user interfaces. ACM, 2004.

[41] A. Thomaz and C. Breazeal, "Teachable robots: Understanding human teaching behavior to build more effective robot learners," Artificial Intelligence, vol. 172, no. 6-7, pp. 716-737, 2008.

[42] K. Huotari and J. Hamari, "Defining gamification: a service marketing perspective," in 16th International Academic MindTrek Conference, 2012. 


\section{APPENDIX}

\section{Pre-Test Questionnaire}

1. Correct the following statement using proper quotation marks in text citation.

2. Properly label the elements of the following citation.

3. If you are searching for information on "Overwatch" game characters, what keywords would you use?

4. If you are looking for information on silent films or Charlie Chaplin, how would you structure your search?

5. You are writing a paper about the video game "No Man's Sky". What would you use as a primary source? What would you use as a secondary source?

6. Pretend that the following segment is from an article:

"Tomorrow, January 7, 3044 will mark the release of the new animal friendly hang-gliders. Animal lovers have already begun gathering at the testing site: Mount Camjeds. The animal friendly handgliders will include custom-sized chairs with safety belts. Each animal will be fitted with a parachute that automatically opens if the animal becomes separated from the glider while in flight."

You see the following sentence in a completely different article:

"The animal friendly hand-gliders will include custom-sized chairs with safety belts."

Would this sentence be considered a summary, direct quote, or paraphrase?

7. Correct the following run-on sentence.

Cake goes well with ice cream they complement each other's flavor.
The three year old declared, You and me don't know how to dance! This is jumping.

Walker, Jeremy S. (2016). Making friends with pythons. Porridge Field, Idaho: National Wildlife Association.
Primary Source:

Secondary Source: 


\section{Post-Test Questionnaire}

1. Correct the following statement using proper quotation marks in text citation.

Grandmother spoke hushedly saying Merlin transformed into a peasant and melted into the unwashed crowd before them as King Arthur looked on flanked by his knights.

2. Properly correct the following citation

Said, Edward W. Culture and Imperialism. Knopf, 1994.

3. You are looking for information about the architecture in renaissance Italy. What keywords would give you the desired results?

4. You are looking for information on Italian architecture but NOT the landscape, how would you formulate your search?

5. You're writing a paper about the film "Die Hard", starring Bruce Willis. What will serve as a primary source?

Primary Source:

Secondary Source:

6. Briefly summarize the following paragraph.

"Nikola Tesla was born in 1856 and died in 1943.

He was born on or around July 9/10 in 1856 in

Smiljan Croatia formerly part of Austria-Hungary. He studied engineering at the Technical University at Graz Austria, and continued studies at the University of Prague until his father's death. During his time in Austria he witnessed a demonstration of a direct-current electric dynamo motor and felt that the machine could be improved by eliminating the commutator and sparking brushes. He had the idea for an induction motor. Tesla built his first working induction motor in 1883. He left Europe for New York and set up a laboratory and workshop in 1887."

7. Correct the following run-on sentence.

Toni Morrison is a professor at Princeton

University, she wrote the novel The Bluest Eye. 